\title{
System of acquisition and processing of signals through of Arduino platform and Matlab (How tool of learning)
}

\section{Sistema de adquisición y procesamiento de señales a través de la plataforma Arduino y Matlab (como herramienta de enseñanza)}

\author{
ARREGUIN-JUÁREZ, Miguel†, HERNÁNDEZ-LÓPEZ, Sandra Paola, SÁNCHEZ-TORRECITAS, \\ Enrique and QUINTANILLA-DOMÍNGUEZ, Joel*
}

Universidad Politécnica de Juventino Rosas, Master of Engineering, Intelligent Systems. Mexico.

ID $1^{\text {st }}$ Author: Miguel, Arreguin-Juárez / ORC ID: 0000-0003-2312-2695

ID $1^{\text {st }}$ Coauthor: Sandra Paola, Hernández-López / ORC ID: 0000-0002-8396-5101

ID $2^{\text {nd }}$ Coauthor: Enrique, Sánchez-Torrecitas / ORC ID: 0000-0002-5395-6749

ID $3^{\text {rd }}$ Coauthor: Joel, Quintanilla-Domínguez / ORC ID: 0000-0003-2442-2032

DOI: $10.35429 / J T I .2020 .20 .7 .19 .27$

Received January 20, 2020; Accepted June 30, 2020

\begin{abstract}
This work presents a real time system of acquisition, monitoring and signal processing based on the synergy of hardware and software. In the stage of signal acquisition, a circuit board was built. This circuit board acquires two signals, one from a phototransistor sensor and other one from an ultrasonic sensor. The sending and processing of the data was through the Arduino platform. A graphical user interface (GUI) using Matlab® was implemented for the stages of monitoring and processing. For these stages two interfaces were designed and implemented with the aim of show the signals of two forms, continuous and digital, and their processing. For the processing stage, several operations such as convolution, median filter and the Fast Fourier Transform were applied to the signal. On the other hand, another aim of the implementation of this system was with the purpose to obtain a didactic tool to complement and support learning in the area of signal processing and thus generate a bigger interest and motivation of the students to practice the knowledge acquired in classes.
\end{abstract}

Resumen

En este trabajo se presenta un sistema de adquisición, monitoreo y procesamiento de señales en tiempo real basado en la sinergia de hardware y software. En la etapa de adquisición se construyó una tarjeta, la cual se encarga de la adquisición de señales provenientes de dos sensores, un fototransistor y uno ultrasónico. Una vez adquiridas las señales, el envío de los datos para el monitoreo y el procesamiento fue a través de la plataforma Arduino. Para las etapas de monitoreo y de procesamiento se diseñó y se implementó una interfaz gráfica de usuario (GUI) mediante el software MatLabß. Para la etapa de monitoreo y procesamiento se diseñaron ventanas para mostrar las señales de forma continua, digital y su procesamiento. En la etapa de procesamiento se realizaron las operaciones de convolución, aplicación de un filtro de medias, así como la transformada rápida de Fourier. Otro de los objetivos de la implementación del sistema de adquisición y procesamiento fue con la finalidad de contar con una herramienta didáctica como complemento y refuerzo en la enseñanza, aprendizaje en el área de procesamiento de señales generando un mayor interés y motivación sobre el alumnado a que se aplique de forma práctica y dinámica la teoría vista en el aula de clases.

Procesamiento de señales, Adquisición de señales, Monitoreo

\footnotetext{
* Correspondence to Author (E-Mail: jquintanilla_ptc@upjr.edu.mx)

$\dagger$ Researcher contributing as first author.
} 


\section{Introduction}

In recent years, communications are the main information tools and they continue to be the most powerful at a social, cultural, political, technical level, etc. (Santos Peñas \& Farias Castro, 2010).

Digital signal processing is an area of science and engineering whose development has increased very rapidly in recent years. This development is mainly due to advances in technology in the field of computing, as well as the manufacture of electronic circuits (Proakis \& Manolakis, 2007).

Physical systems, under the context of signal processing, can be considered as a process in which the input signal is transformed by the system which responds in some way and results in another signal, but an output signal. Under the same context, systems can be classified in two ways: continuous system or discrete system. The continuous system is characterized in that the continuous input signals are transformed into continuous output signals. On the other hand, the discrete system is characterized by transforming the continuous or discrete input signal into a discrete output signal (Oppenheim \& Willsky, 1998).

Signal processing alone cannot do many things. From the outset, it has been mentioned that it is about manipulating signals. Therefore, these signals must be obtained first, so they require sensors to read them. Another step will be to translate these signals that the sensors generate into electrical signals. This is what will be done using a transducer. In addition, if the signal is analog, that is, continuous in time and in amplitude, the signal will need to be digitized or sampled to end up having a set of numerical values every certain time interval, which can be recorded in a computer to be able to be conveniently processed. This is the process for analog-to-digital converter devices. All this process that must be done to have a set of zeros and ones in a computer ready to be manipulated, must often be repeated in reverse, once the signal has been processed (which has manipulated "0" and "1" ) must be returned to the tangible world (Solé i Casals, 2010)
In (Shah \& Vyas, 2014) they propose an algorithm for the detection of objects using image processing, as well as the monitoring of the movement of objects by means of an Arduino-based control. The object detection algorithm was developed in Matlab® using some image processing techniques.

According to (Paucar Guaman, 2018) they developed an interface that makes the acquisition of electrocardiogram signals through the Arduino platform for its subsequent storage in the cloud and finally its processing and visualization in an interface developed in Matlab®.

In (Soares, Valente, Silva, \& Marcelino, 2015) they present an approach to digital sound processing through an Arduino and Matlab®, through some examples they showed how Arduino can be used together with Matlab® to achieve the connection of the world physicist with computing.

In (Loreto Gómez, 2020) she presents a teaching methodology that allows validating the ability of students to apply the knowledge acquired in simulation sessions to physical platforms. The virtual platforms that were developed are based on the Simscape Multibody and Simulink / Matlab® libraries.

(Boluda Segura, 2017) mentions that for the realization of the project I opted for the Carriots platform, they carried out integration tests where the Arduino board, Carriots and freeboard are used, obtaining the temperature readings which are shown to the user, using This platform sends a high temperature alarm to email by SMS, thus obtaining a feasible system for a specific application.

In order to have a didactic tool to complement and reinforce teaching and learning in the area of signal processing, in this work we present a system for acquiring, monitoring and processing signals in real time based on the synergy of hardware and software. For the acquisition stage, a card was built, which is responsible for the acquisition of signals from two sensors, a phototransistor and an ultrasonic one. Once the signals were acquired, the data was sent for monitoring and processing through the Arduino platform. 
For the monitoring and processing stages, a graphical user interface (GUI) was designed and implemented using MatLab®. For the monitoring and processing stage, windows were designed to show the signals continuously, digitally and their processing. In the processing stage, the convolution operations, application of a mean filter, as well as the fast Fourier transform were carried out.

This document is organized as follows: this section shows an introduction to signals and systems, as well as a brief state of the art in which this work is framed. Section 2 describes the development and implementation of the stages of the proposed system. Likewise, section 3 of the results describes the implementation of the signal acquisition and processing system. Finally, section 4 presents the conclusions of the work carried out.

\section{System Proposal}

This article is focused on the result of a signal acquisition and processing system, with an interface developed in Matlab®, in which each of the system's functions were introduced. For the development of the system, different functions were used which are essential to make it work. The signal acquisition and processing system is made up of two stages, one made up of hardware and the other one made up of software, in which the acquisition of physical variables is incorporated by means of two transducers, an infrared sensor for continuous signals. and an ultrasonic sensor for the discrete signals. Said signals are sent through an electronic design or Printed Circuit Board (PCB) to later couple them with the data acquisition system and can be sent to the second block that is made up of the software. Once the signals are conditioned, they are sent to Matlab® with a connection of the data acquisition system (Arduino), through the USB port and RS232 protocol through an established data or COM port, in which the variables and they are processed to later show a result. Figure 1 shows the block diagram of the proposed system.
June 2020 Vol.7 No.20 19-27

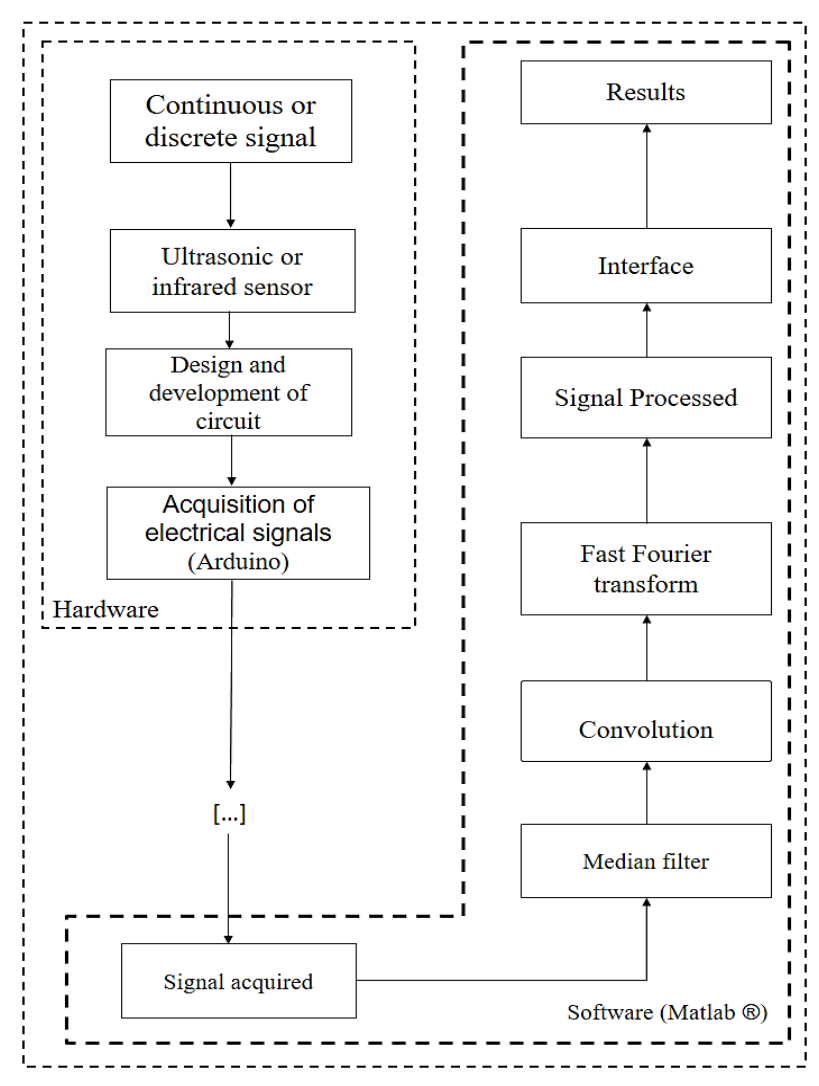

Figure 1 Block diagram of the signal acquisition and processing system

Source: own elaboration [Gimp]

Among the main functions used are the Graphical User Interfaces (GUIDES) with Matlab ${ }^{\circledR}$, which are already integrated into the software. These functions are essential to give a graphical environment to the system and are very similar to the graphical interfaces of Java or $\mathrm{C}$ \# / C ++. Figure 2 shows the menu design of the guide.

\section{System of acquisition and processing of signals}
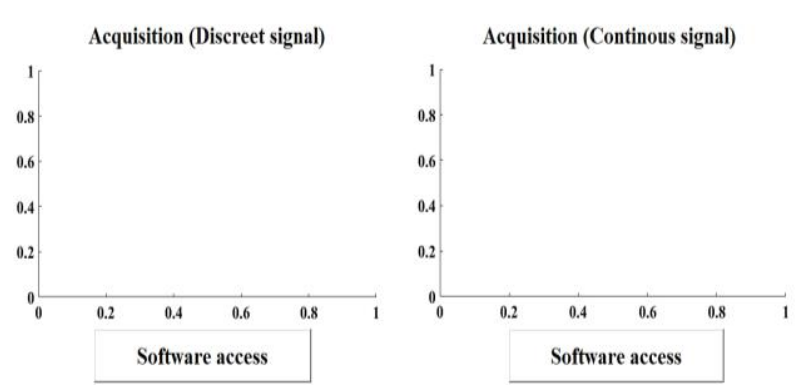

Figure 2 Layout of the Matlab ${ }^{\circledR}$ guide Source: own elaboration [Matlab]

The guide has a main menu, which can give access to the acquisition of signals from an infrared sensor with a phototransistor and an ultrasonic sensor, Figure 3 shows the main menu of the proposed system. 


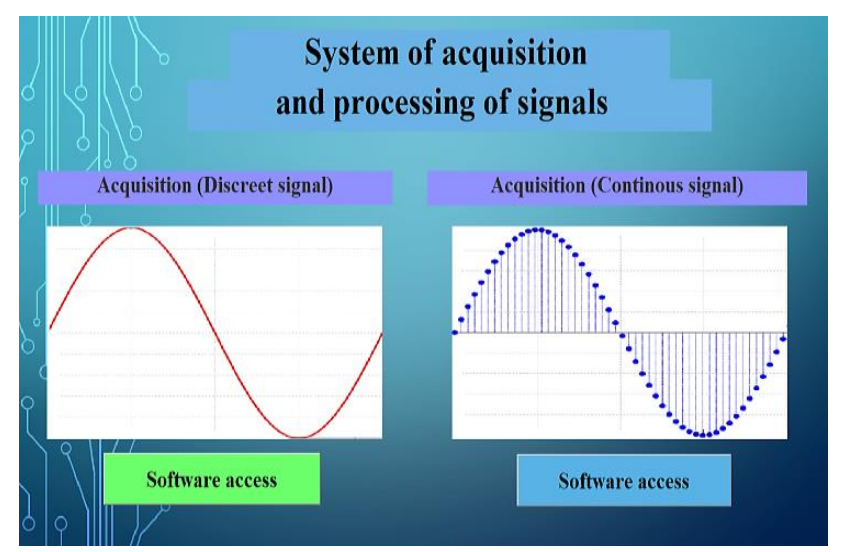

Figure 3 Menu of the signal acquisition and processing system

Source: own elaboration [Matlab]

When the user selects the function of acquisition and processing of a continuous signal, the analog reading is obtained that is obtained from the phototransistor, when the pin of the same is subjected to an intensity of light emitted by the infrared led, it enters saturation mode and allows the current flow, according to the intensity of light that enters through the base of the transistor, so it will be regulated to send an electrical signal to the arduino to acquire the analog signal and be sent through the serial port to the Matlab® software . The data are called from the button assigned in the guide, these data are analog that are between 0 and 1023 values which are converted to a continuous voltage signal with a sampling period which is obtained through the frequency of data acquisition from the arduino, 3 processes are applied to these values.

The first consists of the Fast Fourier Transform (FFT), so that the process of the function is carried out, it is important to acquire the signal sampling in the form of a row vector, taking into account that the signal of the amplitude ( ordinate axis) is found as a function of time (abscissa axis), since the vector is extracted in the same way, for a time interval of $100 \mathrm{~ms}$ in relation to the sampling frequency with a value of $10 \mathrm{~Hz}$ The signal conditioning is carried out in the data acquisition system (Arduino) which has a resolution of 10 bits or 1023 analog values, with a range from $0 \mathrm{v}$ to $5 \mathrm{v}$, detecting voltage ranges of $0.004 \mathrm{v}$, for which it is performed the calculation of the conversion from analog to voltage or amplitude using the following formula: ((Current analog value) * $(5 / 1023))$, it is worth mentioning that the acquisition and conversion process is carried out for the three processing of the continuous signals or infrared sensor.
For the processing of the discrete signals or ultrasonic sensor in the three processes, the conversion is easier because it is a digital signal and only a comparator was used to verify whether there is $(5 \mathrm{v})$ or not $(0 \mathrm{v})$ detection. Once the signal is already converted or conditioned, by means of the Matlab® software and the FFT function, the Fourier transform to the resulting row vector is calculated in which Matlab ${ }^{\circledR}$ executes the application of equations (1) and (two):

$Y(k)=\sum_{j=1}^{n} X(j) w_{n^{(j-1)(k-1)}}$
$X(j)=\frac{1}{n} \sum_{k=1}^{n} Y(k) w_{n^{-}}(j-1)(k-1)$

Equation (1) belongs to the Fourier Transform and equation (2) to the Inverse Fourier Transform where: $y(k)$ and $x(j)$ belong to a continuous independent variable energy signal and $w n=e^{(-2 \pi i) / n}$ to a periodic function in relation to time.

According to (Barajas, 2015) the Fourier coefficients allow the characterization of a continuous signal in time $x(t)$ with the property of periodicity. These coefficients provide the signal information in the frequency domain $\mathrm{x}(\mathrm{f})$. According to Fourier theory, it is possible to take these coefficients and reconstruct a periodic signal. In various cases, you cannot count on a continuous signal in time that offers the opportunity to calculate your Fourier Transform directly. In these cases, samples of the signal under study are taken through the sampling theorem. Mathematically the Fourier transform for a continuous signal at time $\mathrm{x}(\mathrm{t})$ is defined by the equation $x(w)=\int_{-\infty}^{+\infty} x(t) e^{-j w} d t$, while for the analysis of the discrete signal of $\mathrm{N}$ samples $x(n)$ the Discrete Fourier Transform (DFT) is used through the equation $x(k) \sum_{n=0}^{N-1} x(n) e^{-j \frac{2 \pi k n}{N}}$ It is necessary to take into account that when directly implementing the Discrete Fourier Transform (DFT) through an algorithm, little computational efficiency is obtained. For this reason, it is proposed in this article to implement an efficient method for calculating the DFT, taking advantage of its symmetry properties. 
In accordance with the above, the Matlab® software allows the above calculations to be carried out by means of the functions integrated in the same software and allows interaction with the students to be able to see the analysis of the equation, offering visual and practical learning strategies. In the case of the Means and Convolution Filter, the sample of both continuous and discrete signals was acquired with the same Fourier Transform process. In this case, the first seven values of the row vector were taken to apply a Mean Filter, which is evaluated by means of a kernel that contains a vector of 1 row by 3 columns, acquiring the mean of each of the seven values. To calculate the mean of the extreme values it is necessary to fill the row vector with ones and zeros depending on the selection, in this case a function was created in Matlab® to be filled by ones, so that the evaluation kernel is applied correctly and the size of the vectors are equal. In a mathematical way, the evaluation of each of the components of the vector vector was performed according to equation (3):

$\mu=\frac{1}{N} \sum_{i=1}^{N} A i$

Where A corresponds to a random variable vector and $\mathrm{N}$ is the number of scalar observations.

According to (Smith, 1997) a digital filter is a filter that operates on digital signals, with a mathematical operation that takes a sequence of numbers (the input signal) and modifies it producing another sequence of numbers (the output signal). In the application, it separates the signals that were combined with noise (interference), recovery of distorted signals, sound synthesis and audio effect. In this case, for digital and analog filtering, its performance is superior to filters. If the impulse response is known, the filter response to any input can be calculated. If you have a frequency, the discrete time Fourier transform is used.

The applications of digital filters, the area to which the Media Filter belongs, are of utmost importance and also involve mathematics and their interaction with the software will allow a better association with the topic. The third and final processing is the Convolution, which is very similar to the Means Filter.
For Convolution it is also necessary to have a data vector with seven values, which will be evaluated with the help of a convolution kernel that contains values of one, being a vector of 1 row by 3 columns that contains the following structure [ $\left.\begin{array}{lll}1 & 1 & 1\end{array}\right]$, which is intercepted in the values of the vector to be evaluated and the sum of products is obtained in each iteration, giving if a vector of data with the convolution values that were executed from equation (4):

$w(k)=\sum_{j} u(j) v(k-j+1)$

Where $\mathrm{u}$ and $\mathrm{v}$ correspond to the values of two vectors that represent the area of overlap under the points as v slides to $\mathrm{u}$. Algebraically, the Convolution is the same operation as multiplying polynomials whose coefficients are the elements of $u$ and $v$, the sum is over all the $j$ values that lead to legal subscripts for $u(j)$ and $v$ $(\mathrm{k}-\mathrm{j}+1)$.

In summary, the Convolution of signals in the time domain is equivalent to the multiplication of their spectra in the frequency domain; likewise, the multiplication of signals in the time domain is equivalent to the convolution of their spectra in the frequency domain. The convolution is commutative, associative and distributive, (Márquez, 2012).

From the above processes, it can be shown that it is a bit difficult for students to understand the information transmitted by the topic, but through teaching or interactive tools, the applications of digital filters can be more comprehensive. Also have a virtual laboratory that with the help of mathematical equations can observe their behavior based on graphs of results. The vector of data that the user enters (sample), can be of any size. Once the process is carried out and it is shown in the horizontal and vertical axes, which are the windows that the software has, the data is saved in a .csv file or file separated by commas, so that it can be used as a database and the numerical results are extracted by the user or displayed. In Figure 4 you can see the process window of a continuous signal and the results obtained in the graphs. 


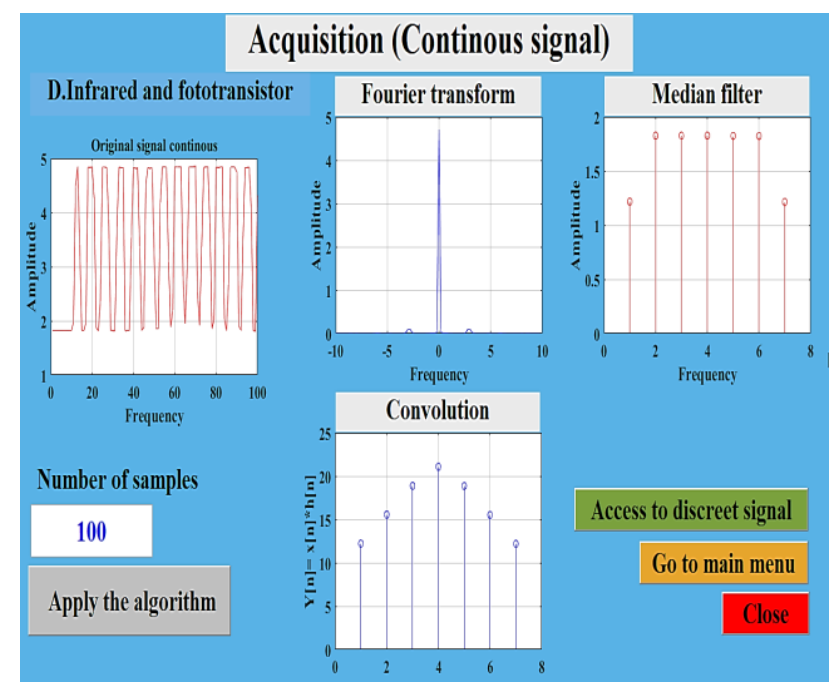

Figure 4 Acquisition and processing of a signal continues Source: own elaboration [Matlab]

Figure 5 shows the graph of the sampling process for the acquisition of the signal in real time.

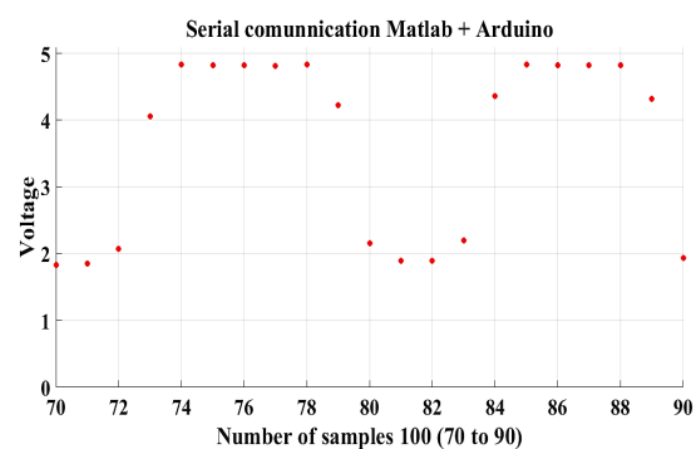

Figure 5 Continuous signal sampling in real time Source: own elaboration [Matlab]

The process to acquire the discrete signal is the same as for the continuous signal and for this an ultrasonic sensor is used, which sends the distance variable that is acquired with the Arduino hardware through the port (RS232).

To carry out the Convolution and Media Filter operation, a train of pulses was generated, with discrete voltage levels of $0 \mathrm{v}$ if no activity is detected and $5 \mathrm{v}$ if it is detected. In addition, a $0.1 \mathrm{v}$ noise signal was synthetically created, which is added to the variable acquired through the arduino serial port, this solves the problem by discretizing $0.1 \mathrm{v}$ values on the falling edge and $5.1 \mathrm{v}$ on the rising edge of the square signal and pulse train. The asynchronous signal provides information that is of great importance for determining electronic systems and applying signal processing. Figure 6 shows the image with the results of the discrete signal acquired.

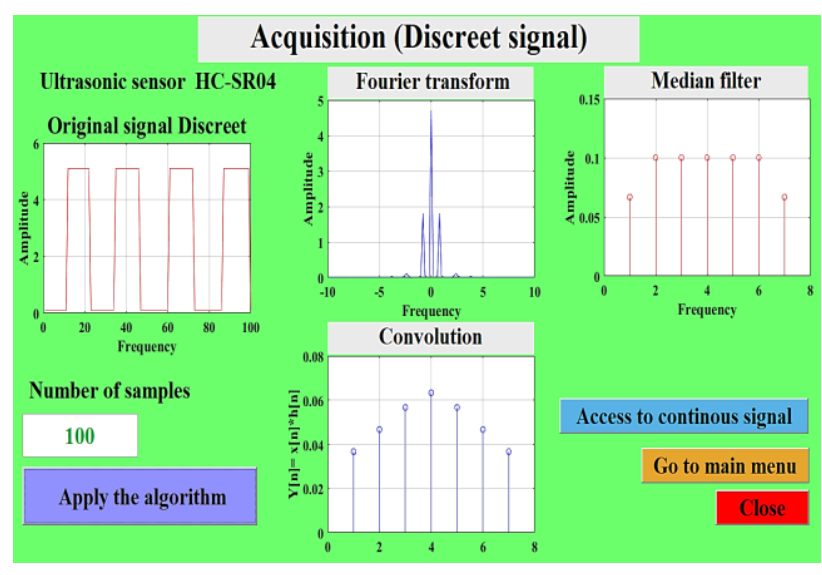

Figure 6 Acquisition and processing of a discrete signal Source: own elaboration [Matlab]

Figure 7 shows the graph of the acquisition of signal sampling in real time.

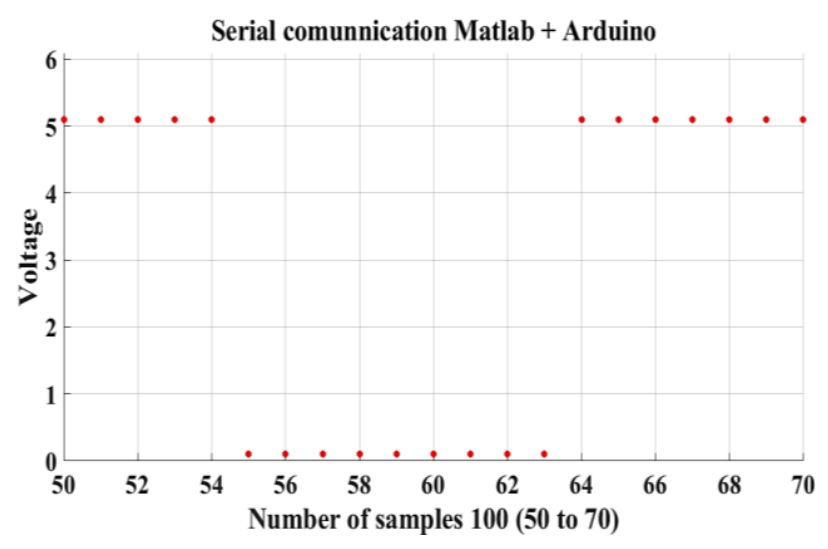

Figure 7 Discrete signal sampling in real time Source: own elaboration [Matlab]

The information generated is stored in text files as shown in Figure 8.

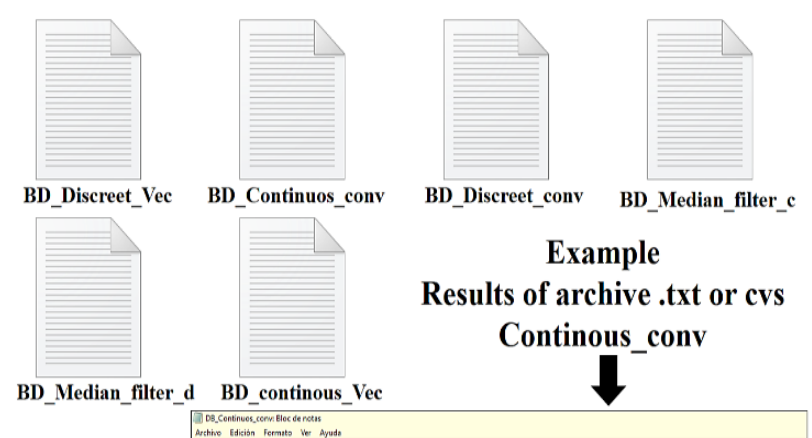

$15.455,18.745,22.019,24.208,21.386,16.8,12.547$

Figure 8 Txt files or comma separated file generated by the software

Source: own elaboration [Matlab] 
For the hardware design, 2 Arduino Uno R3 version boards were placed in order to acquire each of the signals generated by the sensors (photodiode-phototransistor and ultrasonic) contained on the PCB. In addition, a circuit was designed that indicates the connection to the arduino and the data transmission, thus revealing the embedded system created from three important factors: hardware, software, and real-time monitoring (remember that there is a time lag and there is no real-time monitoring), as well as the acquisition of data from them.

\section{Results}

The signal acquisition and processing system involves two products obtained, one made up of software and the other of hardware. The hardware stage consists of the transducers that acquire the physical variables made up of the ultrasonic sensor and the phototransistor, later there are the data acquisition systems or arduinos that integrate their USB output port and their Serial RS232 communication protocol, through which acquired signals are transferred and conditioned so that Matlab® software can work with its due processing, Figures 9 and 10 show the prototype of the system.

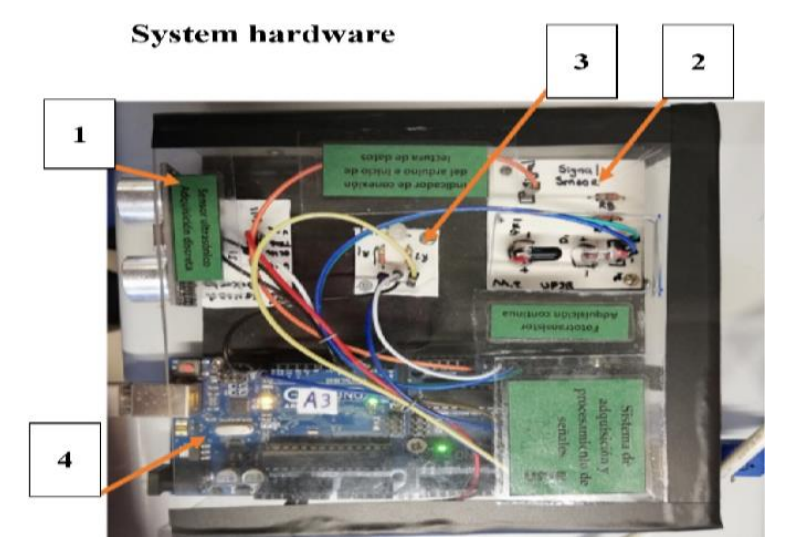

Figure 9 Parts that make up the hardware of the signal acquisition and processing system. (1) Ultrasonic sensor (discrete acquisition), (2) Phototransistor (continuous acquisition), (3) Arduino connection acquisition and data reading start

Source: own elaboration [Gimp]

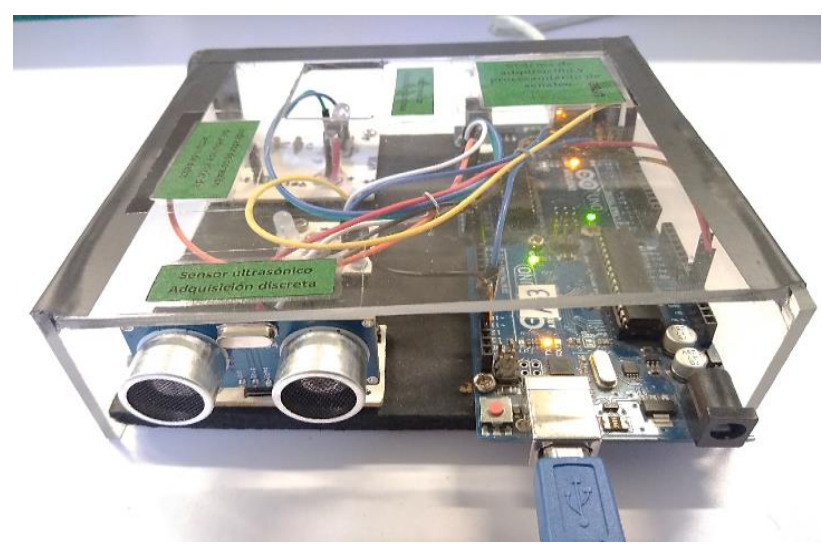

Figure 10 Rear view of the embedded system hardware Source: own elaboration [Gimp]

The software or system developed in Matlab® acquires the signal from the arduino through RS232 communication, executes a window in real time (remember that there is always a small lag in data collection) and as it acquires it, it displays them in a figure that it automatically opens when processing the number of samples required, within the system it saves this signal as a vector of data obtained and displays the signal in its real size. Figure 11 shows the total sample acquisition window, as well as its visualization within the system.

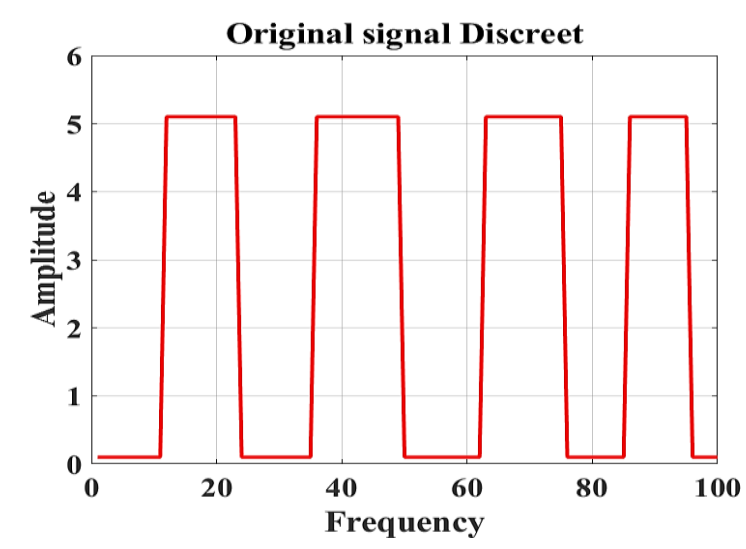

Figure 11 Complete reading of the sampling of a discrete signal in the system

Source: own elaboration [Matlab]

Once the signal is obtained, it is stored in a variable to which the function of each of the processes that it contains is applied. In Figure 12, 13 and 14 the results of the application of the Fourier Transform, Filter of Means are shown. and the operation of the Convolution of a discrete signal. It is important to mention that the same happens when the process is carried out with a continuous signal. 


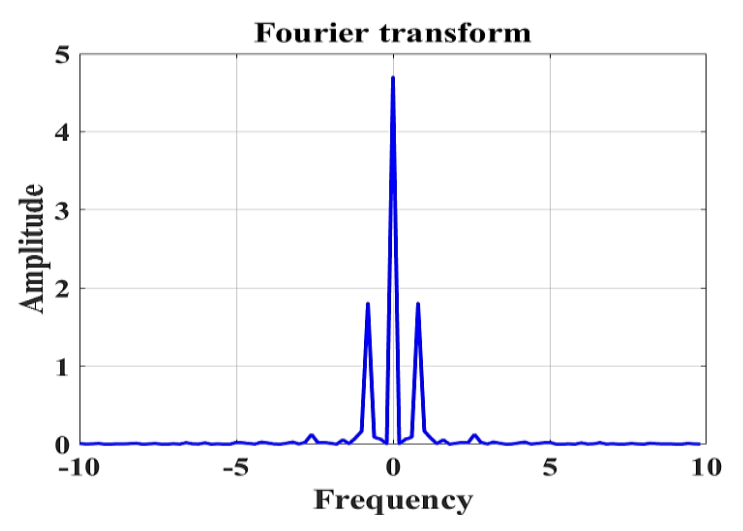

Figure 12 Application of the Fourier transform Source: own elaboration [Matlab]

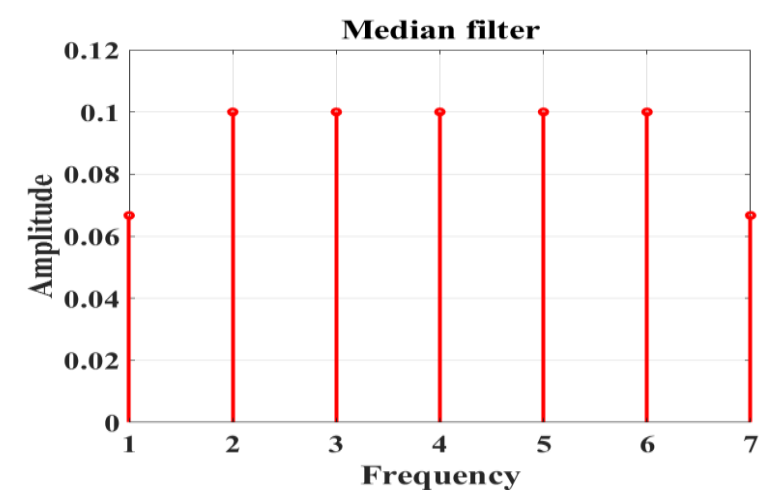

Figure 13 Media filter application Source: own elaboration [Matlab]

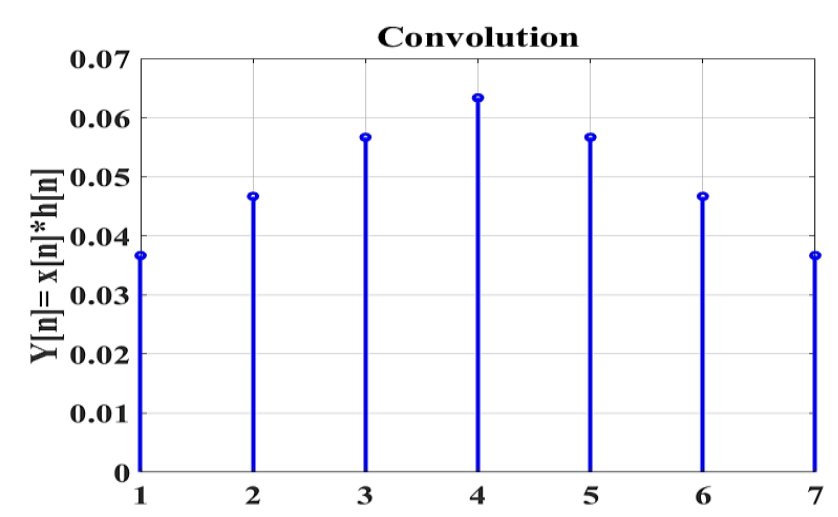

Figure 14 Application of the convolution Source: own elaboration [Matlab]

As can be seen, the intervention of the theory through the software has enriching results for the training of the student, the signals are the result of mathematical applications and these can be done through programming or with the use of Matlab's own functions ${ }^{\circledR}$, which are already integrated into the program, in addition to observing their behavior according to the mathematical changes that are made in a quick and easy way.

\section{Conclusions}

Signal processing and algorithm programming are areas that have a great impact in modern technology. On the other hand, the process of technological advancement of society can be clearly observed, therefore, knowing the principles of programming and the analysis of signals, they are generated in a virtual matrix laboratory, is the great step to start in this great world of knowledge. An area of interest for these subjects and one that includes technological advances is voice recognition found in the most current security devices and in the detection of the user's voice frequencies.

The design and construction of a data acquisition system and its interface in Matlab ${ }^{\circledR}$ meets the objective for which it was developed, which is to teach signal processing to students who are just entering the telecommunications area, as well as to reaffirm the interest of those who have already started in the world of telecommunications.

It is important to mention that the use of an acquisition system from using the Arduino platform will allow the student to replicate it at a lower cost, since it uses relatively cheap materials and can be adapted to various platforms, it is also important to note that the system Acquisition, processing and display shows the principle of an embedded system and due to the capabilities of both Arduino, electronics and Matlab ${ }^{\circledR}$ an even more complete or robust system can be generated.

\section{References}

Barajas, J. E. (2015). Series y Transformada de Fourier para señales Continuas y Discretas en el Tiempo Algoritmos para el desarrollo de ejercicios prácticos. Aquino, Bogotá D.C., Colombia: OmniaScience (Omnia Publisher SL).

Boluda Segura, J. (2017). Aplicación de las tecnologías IOT en un sistema de riego en parcela. 0-71.

Loreto Gómez, G. (2020). Enseñanza de la teoria de control lineal utilizando simulaciones y plataformas de sistemas aero-propulsados. Padi Boletín Científico de Ciencias Básicas e Ingenierías del ICBI, 89-97. 
Márquez, J. E. (Noviembre 2012). Principios de las comunicaciones. Merida, Venezuela: Facultad de ingenieria, publicaciones.

Oppenheim, A., \& Willsky, A. (1998). Señales y Sistemas. Naucalpan de Juárez: Prentice Hall Hispanoamericana.

Paucar Guaman, P. (2018). Desarrollo de una interfaz de visualización en matlab para señales ECG utilizando el sistema arduino almacenadas en un sitio web. Guayaquil.

Proakis, J., \& Manolakis, D. (2007). Tratamiento digital de señales. Madrid: Pearson Prentice Hall.

Santos Peñas, M., \& Farias Castro, G. (2010). Laboratorios virtuales de procesamiento de señales. Revista Iberoamericana de Automática e Infórmatica Industrial, 91-100.

Shah, P., \& Vyas, T. (2014). Interfacing of Matlab with Arduino for Objrct Detection Algortihm Implementation using Serial Comunication. International Journal of Engineering Research \& Technology, 10671071.

Smith, S. (1997). The Scientist \& Engineer's Guide to Digital Signal Processing. California Technical Pub.

Soares, S., Valente, A., Silva, S., \& Marcelino, S. (2015). Digital Sound Processing using Arduino and Matlab. Science and Information Conference 2015, (págs. 1184-1191). London, UK.

Solé i Casals, J. (18 de Octubre de 2010). Procesamiento de señal. Obtenido de https://www.investigacionyciencia.es/blogs/tec nologia/20/posts/procesamiento-de-seal-10223 